\title{
Work Values of Baby-Boomers and Generation X of the Chinese Community in Malaysia
}

\author{
Lim Yet-Mee \\ Department of Management, Universiti Tunku Abdul Rahman, Selangor D.E., Malaysia \\ Tel: 60-03-9019-4722Ｅ-mail: limym@mail.utar.edu.my \\ Pek Chuen-Khee (Corresponding author) \\ Department of Economics, Universiti Tunku Abdul Rahman, Selangor D.E., Malaysia \\ Tel: 60-012-682-3811 E-mail: pekck@mail.utar.edu.my
}

Yee Aik-Phoay

Faculty of Business \& Accountancy, INTI International University College

Negeri Sembilan D.K., Malaysia

Tel: 60-012-489-9108 E-mail: benny_yee@hotmail.com

\begin{abstract}
Organizations in the era of globalization require not only an efficient and cohesive pool of workforce but also one with strong work values. The said workforce in general comprises the Baby-boomers (aged 40 to 60 years) and Generation $\mathrm{X}$ (aged 25 to 39 years) workers. The Generation X undoubtedly, will be slowly replacing the boomers in the labour force. Rightfully so, the former would be playing a more active and dynamic role in the labour market. Hence, a comprehensive study of their work values with comparison to their Baby-boomers counterpart is timely. This study adopted Mantech's (1983) Work Value Questionnaire to elicit the responses of the target groups. The work values of the boomers and X-ers of the working ethnic Chinese in Malaysia may not be significantly different but findings have sufficient evidence that the X-ers are more money-oriented than the boomers though both generations may agree that work values categories which are more extrinsic and materialistic in nature are more important to them. The results of this study will be helpful for the organizations, particularly those of the Chinese-based to review, if required, their current human resource policies.
\end{abstract}

Keywords: Work values, Baby-boomers, Generation X, Working ethnic Chinese

\section{Introduction and research objectives}

Work values per se are acquainted with a wide scope of definitions. Furnham et. al. (2005) reviewed that though there exists extensive literature on work values, disagreement on its meaning and measurement remains unresolved. In the works of Selmer \& De Leon (1996) and Parsons et. al. (1999), work values were envisaged as cultural values while George \& Jones (1997) perceived it as personal values. However, for the purpose of this study, work values comprised one's preferences for the type of work or work environment, beliefs about the importance of the prerequisites in a work situation and the guiding principles of job related decisions, action and behaviours. This definition was rather analogous with the one used by Dose (1997) in her study on the application of work values to organizational socialization.

The measurement and assessment of work values differ from literature to literature. Harrington-O'Shea Career Decision Making System which consists of 14 work values (creativity, good salary, high achievement, independence, job security, and etc.) was used by Lebo et. al. (1995), to examine high school students' selected work values in Australia, Canada, Finland, France, Norway and the United States, and found that work values are more similar than otherwise across countries and cultures. The 25-item Manhardt Scale (risk taking, value of ample leisure, job prestige, autonomy, working condition and routine, and career advancement and etc.) was used by Abu-Saad \& Isralowitz (1997) to study gender as a determinant of work values among university folks in Israel and found that the perception of gender-based differences in work values has to be revisited. Chen et. al. (2000), employed Super's Work Value Inventory with 45 attributes such as reasonable boss, seeking result, stable work, pay increase, work freedom and etc. to assess the Taiwanese undergraduates' perception of work values and found that supervisory relations, work surroundings and way 
of life to be the top three values appreciated by the respondents. Wong \& Chung (2003) however, used a combination of Hofstede Value Survey Module and Chinese Value Survey with five underlying dimensions such as congenial job context, job status and prospects and etc., to study the work values of Chinese food service managers in Hong Kong and revealed that secure employment, pleasant working environment, high earning and good work relations with supervisors and peers are the more important work values.

Some other researchers have been dynamic in designing their own assessment methods, namely Elizur (1996), employed a self-constructed 24-item Work Value Questionnaires (advancement, personal growth, contribution to society, esteem, convenient hours and etc.) to look at the relationship between work values and commitment, revealed that there exists stronger correlation between commitment and cognitive than instrumental work values. Nevertheless, for the purpose of this study, the Mantech (1983) 37-items Work Values Questionnaire with an addition of four attributes namely opportunity to work in teams, honesty and integrity, ethical behaviour at work, and emphasis on quality, identified by a focus group, was employed to study the work values of two generations of Chinese workforce in Malaysia. These 41-work values items were then categorized into four main groups; work relationship, influence and advancement, financial and working conditions, and autonomy and use of skills, as identified by Furnham et. al. (2005).

This study focused on the ethnic Chinese in Malaysia as a respond to the work by Tuch \& Martin (1991) which noted that there have not been many studies addressing the issues of work values with regards to the Eastern world and ethnic groups.

The Malaysian Chinese pools up 24 percent of the 24 million population (www.cia.gov, 2005) in the country which has a labour force of 10.5 million (www.cia.gov, 2004) workers. As one of the largest ethnic group in Malaysia that contributes to the nation's manpower, investigating the work values of the Chinese community in Malaysia is definitely of great interest.

This study intended to answer the following research questions on the work values of the Baby-boomers and Generation $\mathrm{X}$ of the Chinese community in Malaysia:

\section{Research Question 1:}

Is there any significant difference in the degree of importance of the four categories of work values between the Baby-boomers and Generation X, respectively?

\section{Research Question 2:}

Are there any significant differences among the degree of importance for the four categories of work values within each generation?

\section{Research Question 3:}

Are there any significant differences among the ranking of importance for the four categories of work values within each generation?

The last research question intended to seek a deeper understanding on the importance of the work values categories as rating the categories of work values highly (lowly) to indicate their degree of importance, does not necessary reflect high (low) rank levels in terms of their importance.

Baby-boomers and Generation X are the two existing generations in the current pool of the workforce. In the work of Smola \& Sutton (2002), the work values identified for comparison of the two generations of workers were desirability of work outcomes, pride in craftsmanship and moral importance of work. The period defining generation of Baby-boomers and Generation X varies. Based on various literature sighted, the Boomer's birth may range anywhere from 1940 to 1946 and end in 1960 or 1964. For the case of Generation X, it begins somewhere in the early 1960s and end in 1975, 1980, 1981, or 1982. However, for the purpose of this study, boomers are people aged between 40 to 60 years old, while X-ers comprises those between 25 to 39 years of age (Kotler \& Keller, 2006). The former embraces the idea of entitlement and expecting the best from life (Kupperschmidt, 2000), while the latter survives through rapid changes and insecurity, and lack of strong mores leading them into becoming more individualistic (Jurkiewicz \& Brown, 1998). The results of the study of Smola \& Sutton (2002) revealed that generational work values do vary and it does change as one ages, and saw that there has been an increased need for balance work and personal goals within the American labour arm. Loscocco \& Kalleberg (2001) found that older men gave more commitment to their jobs than younger men in Japan and the United States. This phenomenon was also revealed in this study implying that older Malaysians give more obligations to work than their younger compatriots do.

\section{Methodology}

A group of randomly selected Baby-boomers and Generation X of the ethnic Chinese in the Klang Valley responded to a self-administered questionnaire comprising 41 work values identified from Mantech (1983) 37-item Work Value Questionnaires and four work values i.e. opportunity to work in teams, honesty and integrity, ethical behaviour at work, 
and emphasis on quality. These work values were classified into four major categories namely, work relationships, influence and advancement, financial and working conditions, and autonomy and use of skills. Work relationships comprised 15 sub-items (relationship with work colleagues, harmony, feedback, opportunity to work in teams and etc.), influence and advancement with nine sub-items (influence within work organisation, high job status, advancement and chances for promotion, managerial respect, and etc.), financial and working conditions with 12 sub-items (benefits, pay, human resource support, company image and etc.), and autonomy and use of skills with five sub-items (independence, autonomy, job interest and etc.).

The respondents were interviewed in the months of August to October 2005 and asked to rate the importance $(1=$ not important to $6=$ extremely important) of each work value in making them happy and contented, and guiding their job-related behaviours and decision-making, in their work The reliability of the categories of work values scale was at Cronbach's alpha 0.85 . The respondents then ranked the four categories in order of their importance to them (" 1 " being the most important, " 2 " being second most important and " 4 " being the least important.).

A total of 150 respondents from the working class of the ethnic Chinese answered the questionnaires. With a respondent mean age of 34 years, this sample comprised 30 percent of working Baby-boomers and 70 percent of working Generation X. The vast majority were females $(60.0$ percent $)$ and males $(40.0$ percent $)$ whom 10 percent of the both sexes had been in the workforce for a year or less, 26 percent between one to five years, 29 percent between five to 10 years, while those who had been in the labour force for 10 to 20 years was 22 percent and 13 percent of them had served the workforce for more than 20 years. When analyzing the data on years serving their existing work organizations, the same respondents revealed that 40 percent of them had served their existing work place for a year or less, 36 percent for one to five years, 11 percent for five to 10 years and the balance of 13 percent for 10 years and above.

Majority of the respondents (68 percent) were university graduates with at least a first degree or more. Only about nine percent of them were either with no formal education (one percent), or primary education (two percent) or secondary education (six percent). A total of 23 percent of the sample respondents were equipped with certificates, diploma or professional qualifications.

The statistical methods used to process the collected data were descriptive statistics and t-test analysis with the Statistical Package for the Social Sciences (SPSS) and Tukey Kramer procedure with Prentice Hall Statistics (PHStats).

Four separate t-test analysis were ran to answer the first research question, i.e. if there exists any difference in the degree of importance of work relationships between the two generations and the same for the three other categories, namely influence and advancement, financial and working conditions, and autonomy and use of skills.

The Tukey Kramer procedures were used to obtain the results to answer the second and last research questions i.e. to check if all the four categories of work values do differ in their degree of importance (second research question) and ranking of importance (third research question), respectively, for each of the individual generations. Four such procedures were processed.

\section{Results}

Research Question 1: Is there any significant difference in the degree of importance of the four categories of work values between the Baby-boomers and Generation X, respectively?

The results indicated that at the five percent level of significance, there were no significant differences in the degree of importance of the four categories of work values respectively, between the Baby-boomers and Generation X. These implied that all the work values as individual categories were equally important to the two generations. The mean scores of the four categories of work values for the boomers and X-ers respectively were $(4.93,5.02)$ for working relationships, $(4.66,4.75)$ for influence and advancement, $(4.91,5.02)$ for financial and working conditions, and $(4.97,5.09)$ for autonomy and use of skills.

Research Question 2: Are there any significant differences among the degree of importance for the four categories of work values within each generation?

According to the Tukey Kramer procedure, the Baby-boomers revealed that there were no significantdifferences among the degree of importance for all the categories of work values at the level of significance 0.05 , indicating that work relationships, influence and advancement, financial and working conditions, and autonomy and use of skills, as work values are equally important to them. However, if the descriptive statistics were used, autonomy and use of skills (mean $=4.97$ ) scored the highest degree of importance among all the work values categories, followed by work relationships (4.93), financial and working conditions (4.91) and the least, influence and advancement (4.66).

The results for the Generation $\mathrm{X}$ however, revealed slight differences from the boomers at the similar level of significance. It was found that at least two or more work values categories do not share similar degree of importance in the X-ers. Tukey Kramer procedure revealed that work relationships, financial and working conditions and, autonomy and use of skills, each had significant difference in the degree of importance when compared respectively to influence 
and advancement. However, there had been no significant difference when work relationships, and financial and working conditions were compared. Similar results were found for the comparisons between work relationships, and autonomy and use of skills, and between financial and working conditions, and autonomy and use of skills respectively.

Nevertheless, the descriptive statistics revealed that for the Generation X, the degree of importance of the work values were rated highest for autonomy and use of skills (mean $=5.09$ ), followed by financial and working conditions $(5.03)$, work relationships (5.02) and influence and advancement (4.76).

Research Question 3: Are there any significant differences among the ranking of importance for the four categories of work values within each generation?

The results of this research question revealed a different pattern for the boomers. It was shown that boomer's ranking in the importance of the four work values categories revealed significant differences $(\mathrm{alpha}=0.05)$ in at least two or more work values categories according to Tukey Kramer procedures.

For the boomers, work relationships work value category was ranked to be more important than influence and advancement. The latter work value category was also ranked a less important work value category than financial and working conditions, and autonomy and use of skills when compared respectively. The ranking of the importance of work relationships however was not significantly different from financial and working conditions, and autonomy and use of skills respectively. From these results, it was not possible to draw an ordinal pattern of the ranking of the importance of the various work values categories and this may be contributed by the boomers' results in research question two, which revealed insignificant differences among the degree of importance of the work values.

However, from the mean values of each work values categories, the ranking of the importance were financial and working conditions (mean $=1.95)$, followed by work relationships $(2.25)$, autonomy and use of skills $(2.59)$, and influence and advancement (3.21).

The results from the X-ers were consistent with those of the second research question, and this aided the study in further understanding the importance of the work values categories. Similar to the boomers, Generation X's ranking in the importance of the four work values categories revealed significant differences (alpha $=0.05)$ in at least two or more work values categories. The work relationships, and influence and advancement do not show any significant difference in terms of their ranking of importance. Similar results were gathered for the pair of work relationships, and autonomy and use of skills and pair of influence and advancement, and autonomy and use of skills respectively.

However, the comparisons between working relationships, and financial and working conditions, and between influence and advancement, and financial and working conditions respectively, indicated that there are significant differences between the rankings of importance of the two work value categories with financial and working conditions being ranked higher than working relationships, and influence and autonomy respectively. The financial and working conditions work value category was also ranked higher when compared to autonomy and use of skills.

From these results, an ordinal pattern of ranking was possible with financial and working conditions (mean $=1.92)$ being ranked the higher work value category than the other three work values categories (work relationships (2.50), and autonomy and use of skills (2.70) and, influence and advancement (2.87)), when compared respectively. Coupled with the descriptive statistics and findings from the second research question which indicated the insignificant differences among the degree of importance of work values categories of work relationships, financial and working conditions, and autonomy and use of skills, an insight revealing that financial and working conditions was the most important work value category, followed by work relationships, and autonomy and use of skills and, influence and advancement as the least important work value for the Generation X, was suggested.

\section{Discussions and conclusions}

The Baby-boomers and Generation X of the working ethnic Chinese in Malaysia have in common similar understanding and application of work values when a between- comparison was studied. Though the within-comparison studies in the degree of the work values categories importance saw a slight difference, the ranking of the importance of the work values were similar for the two generations.

The results of the study in attempting to address the issue of significant differences in the degree of importance of the four work values categories revealed that between both generations, these work values were equally important to them. The findings showed that both the generations might share similar life principles, which may have moulded their perception of work. This possibility may be consistent with the findings from the works of Wong \& Chung (2003) and Loughlin \& Barling (2001).

Wong \& Chung (2003), articulated that the ethnic Chinese has shared a common cultural value since ages ago, which has contributed to the formation of a clear and consistent system for generations, while Loughlin \& Barling (2001) found that one of the major factors influencing work values had been the family influences. Undeniably, the boomers are the parents of the X-ers, whom may have guided their children in their work values through the sharing of strong 
cultural and life values. Confucianism, which is still the basic doctrine of the Chinese families, stressing on filial piety, would have made the inheritance of these strong Chinese cultural values possible.

The work of Smola \& Sutton (2002) which compared the work values between 1974 and 2002, prompted the possibility of a study based on their definition of "generation" to be carried out on the ethnic Chinese in future. The findings then compared with those of Smola \& Sutton, which suggested that there were some generational work values differences, may reveal new and innovative insights to research of similar areas.

The degree of importance of the four work values categories based on the ratings within each generation, compared, suggested slight difference between the boomers and X-ers. The former rated autonomy and use of skills as having the highest degree of importance followed by work relationships, then financial and working conditions, and the least, influence and advancement. The slight difference suggested was the $\mathrm{X}$-ers while maintaining the highest and least degree of work values categories importance as the boomers, rated financial and working conditions higher than work relationships. This suggested that boomers weigh work relationships, which are non-materialistic, heavier than financial and working conditions, which are materialistic in nature, as compared to X-ers whom are otherwise in their preference. These findings may indicate that the younger generation of working Chinese is more prone to wealth and material accumulation than the boomers, which is quiet a natural behaviour of the young but less for the boomers whom may have saved sufficiently. This implies that future human resource rewards and compensation should emphasize more on extrinsic rewards to motivate the younger workforce while intrinsic rewards will do fine for the senior staff.

Rating a work value category as more important than the others does not necessary mean that it ranked higher. Though from the findings in the degree of work values categories importance, autonomy and use of skills was rated highest, it was not been ranked alike. This work value ranked third within each of the both generations, whom shared similar ranking in the importance of the four work values categories. Financial and working conditions was ranked the most important work value categories (boomer's mean $=1.95, \mathrm{X}$-ers mean $=1.92)$, followed by work relationships $(2.26$, $2.50)$, then autonomy and use of skills $(2.59,2.71)$ and the least important, influence and advancement $(3.21,2.87)$.

From the findings, it is shown that though autonomy and use of skills was rated the most important work values categories, it failed to be ranked the top, but which, was replaced by financial and working conditions. This implies to the human resource policy makers that the ethnic Chinese, regardless of boomers or X-ers, viewed the degree of importance to be different from the ranking of importance of work values categories. The ethnic Chinese may agree that autonomy and use of skills, which are intrinsic in nature, is vital as a work value category for the creation of a motivated workforce, but financial and working conditions, which are more extrinsic in nature, would be even more essential for the making of a productive and effective labour force.

In conclusion, the work values of Baby-boomers and Generation X of the working ethnic Chinese in Malaysia may not be significantly different but findings have sufficient evidence that the X-ers are more money-oriented than the boomers though both generations may agree that work values categories which are more extrinsic and materialistic in nature are more important to them.

\section{References}

Abu-Saad, I., \& Isralowitz, R.E. (1997). Gender as a determinant of work values among university students in Israel. Journal of Social Psychology, 137 (6), 749-763.

Chen, J.S., Chu, H.L., Kay., Wu, W.C. (2000). Tourism students' perceptions of work values: a case of Taiwanese universities. Journal Contemporary Hospitality Management, 12/6, 360-365.

Dose, J. (1997). Work values: an integrative framework and illustrative application to organizational socialization. Journal of Occupational and Organizational Psychology, 70, 219-241.

Elizur, D. (1996). Work values and commitment. International Journal of Manpower, 17(3), 25-30.

Furnham, A., Petrides, K.V., Tsaousis, I., Pappas, K., \& Garrod, D. (2005). A cross-cultural investigation into the relationships between personality traits and work values. The Journal of Psychology, 139(1), 5-32.

George, J., \& Jones, G. (1997). Experiencing work: Values, attitudes, and moods. Human Relations, 50, 393-416.

Jurkiewicz, C. E., \& Brown, R.G. (1998). GenXers vs. boomers vs. matures: generational comparison of public employee motivation. Review of Public Personnel Administration, 18, 18-37.

Kotler, P., \& Keller, K.L. (2006). Marketing Management 12 ed. Pearson International Edition, p236.

Kupperschmidt, B.R. (2000). Multigeneration employees: strategies for effective management. The Health Care Manager, 19, 65-76.

Lebo, R.B., Harrington, T.F., \& Robert, T. (1995). Work values similarities among students from six countries. The Career Development Quarterly, 43(4), 350. 
Loscocco, K.A., \& Kalleberg, A.L. (1988). Age and meaning of work in the United States and Japan. Social Forces, 67:2, 337-356.

Loughlin, C., \& Barling, J. (2001). Young workers' work values, attitudes, and behaviours. Journal of Occupational and Organizational Psychology, 74, 543-558.

Mantech. (1983). Work Values Questionnaire. Auckland, New Zealand: Author.

Parsons, C., Cable, D., \& Wilkerson J. (1999). Assessment of applicant work values through interviews. Journal of Occupational and Organizational Psychology, 72, 561-566.

Selmer, J., \& De Leon, C. (1996). Parent cultural control through organizational acculturation. Journal of Organizational Behavior, 17, 557-572.

Smola, K.W., \& Sutton, C.D. (2002). Generational differences: revisiting generational work values for the new millennium. Journal of Organizational Behavior, 23, 363-382.

Tuch, S.A., \& Martin, J.K. (1991). Race in the workplace: black/white differences in the sources of job satisfaction. Sociological Quarterly, 32, 103-116.

Wong, C.K., Simon., \& Chung, K.H., Manson. (2003). Work values of Chinese food service managers. International Journal Contemporary Hospitality Management, 15/2, 66-75.

Table 1. Respondents' Years in Workforce

\begin{tabular}{|l|c|}
\hline Years in Workforce & $\begin{array}{c}\text { Percentage of } \\
\text { Respondents (\%) }\end{array}$ \\
\hline Less than 1 year & 10 \\
\hline Between 1 to 5 years & 26 \\
\hline Between 5 to 10 years & 29 \\
\hline Between 10 to 20 years & 22 \\
\hline More than 20 years & 13 \\
\hline Total & 100 \\
\hline
\end{tabular}

Table 2. Respondents' Years of Service in Existing Work Organization

\begin{tabular}{|l|c|}
\hline $\begin{array}{c}\text { Years of Service in Existing } \\
\text { Work Organization }\end{array}$ & $\begin{array}{c}\text { Percentage of } \\
\text { Respondents (\%) }\end{array}$ \\
\hline Less than 1 year & 40 \\
\hline Between 1 to 5 years & 36 \\
\hline Between 5 to 10 years & 11 \\
\hline 10 years and above & 13 \\
\hline Total & 100 \\
\hline
\end{tabular}

Table 3. Respondents' Educational Qualification

\begin{tabular}{|l|c|}
\hline \multicolumn{1}{|c|}{ Educational Qualification } & \multicolumn{1}{c|}{$\begin{array}{c}\text { Percentage of } \\
\text { Respondents (\%) }\end{array}$} \\
\hline No formal education & 1 \\
\hline Primary & 2 \\
\hline Secondary / Diplomas & 6 \\
\hline $\begin{array}{l}\text { Certificates / } \\
\text { Professional qualifications }\end{array}$ & 68 \\
\hline $\begin{array}{l}\text { Bachelor's / Master's / Doctorate } \\
\text { Degree }\end{array}$ & 100 \\
\hline Total & \\
\hline
\end{tabular}


Table 4. Mean Scores for the Degree of Importance on Each Work Value Category

\begin{tabular}{|l|c|c|}
\hline \multicolumn{1}{|c|}{ Work Value Category } & Baby-boomers & Generation X \\
\hline Working Relationships & 4.93 & 5.02 \\
\hline Influence and Advancement & 4.66 & 4.75 \\
\hline $\begin{array}{l}\text { Financial and Working } \\
\text { Conditions }\end{array}$ & 4.91 & 5.02 \\
\hline Autonomy and Use of Skills & 4.97 & 5.09 \\
\hline
\end{tabular}

Table 5. Mean Scores for the Ranking of Importance on Each Work Value Category

\begin{tabular}{|l|c|c|}
\hline \multicolumn{1}{|c|}{ Work Value Category } & Baby-boomers & Generation X \\
\hline Working Relationships & 2.25 & 2.50 \\
\hline Influence and Advancement & 3.21 & 2.87 \\
\hline $\begin{array}{l}\text { Financial and Working } \\
\text { Conditions }\end{array}$ & 1.95 & 1.92 \\
\hline Autonomy and Use of Skills & 2.59 & 2.70 \\
\hline
\end{tabular}

